\title{
ZINC REDUCTION AS AN ALTERNATIVE METHOD FOR AMS RADIOCARBON DATING: PROCESS OPTIMIZATION AT CIRCE
}

\author{
F Marzaioli ${ }^{1} \bullet \mathrm{G}$ Borriello $\bullet$ I Passariello $\bullet$ C Lubritto $\bullet \mathrm{N}$ De Cesare $\bullet$ A D'Onofrio $\bullet$ F Terrasi \\ Dipartimento di Scienze Ambientali, Via Vivaldi 43, 81100 Caserta, Italy.
}

\begin{abstract}
The pretreatment of samples for radiocarbon measurements, transforming a variety of materials into graphite solid targets, represents a critical point in the accelerator mass spectrometry (AMS) procedure. We describe the new, state-ofthe-art CIRCE AMS preparation laboratory, particularly the setup and optimization of an alternative method, the zinc reduction method, for graphite target production, compared to the more common hydrogen reduction method. Measured ${ }^{14} \mathrm{C}$ values on standard and blank samples reduced via zinc reaction revealed mean background levels, accuracy, and sensitivity comparable to those obtained by our conventional hydrogen reaction lines. Zinc line reduction at the CIRCE laboratory represents an effective and powerful alternative to the conventional hydrogen reduction, ensuring higher sample throughput with lower costs at a comparable performance level.
\end{abstract}

\section{INTRODUCTION}

Cultural heritage studies and environmental sciences (i.e. biogeochemical cycles assessment, anthropogenic impact on the cultural heritage, and environment assessment) are becoming 2 of the major fields in which physics methodologies, like ion beam analysis and accelerator mass spectrometry (AMS), are becoming crucial analyses for clarifying keyhole mechanisms (Tuniz et al. 1998; Andersen and Demortier 2004; Calzolai et al. 2006). Regarding the carbon biogeochemical cycle, both naturally- and bomb-produced radiocarbon can be used to study dynamics of the different reservoirs contributing to the global (biogeochemical and/or geochemical) cycle (Hughen et al. 1998; Randerson et al. 2002; Druffel et al. 2004). Reduction of the requested mass of sample needed for ${ }^{14} \mathrm{C}$ analysis has led AMS to become a feasible tool for the measurement of a series of samples with low carbon contents, a characteristic of most environmental sciences studies (i.e. soil organic matter [SOM] fractions and respired $\mathrm{CO}_{2}$ [Trumbore 2000]).

At the Department of Environmental Sciences (DSE) of the Second University of Naples, ${ }^{14} \mathrm{C}$ AMS research has been performed over the last decade both for archaeological and environmental applications (Lubritto et al. 2004; Marzaioli et al. 2005). In November 2004, the Centre for Isotopic Research on Cultural and Environmental Heritage (CIRCE) was established. CIRCE is equipped with an AMS system based on a 9SDH-2 Pelletron Tandem accelerator (Terrasi et al. 2007) installed in 2005 and at present in routine operation.

The treatment protocol for the ${ }^{14} \mathrm{C}$ AMS analysis of solid samples usually comprises 3 main steps:

1. Chemical separation and purification according to sample type, with the aim of external carbon contamination suppression and/or isolation of the fraction of carbon of interest (Green 1963; Longin 1971; Mook and Streurman 1983; Fowler et al. 1986; Hoefs 1987; Six et al. 2002);

2. Oxidation of the sample carbon to $\mathrm{CO}_{2}$ (via combustion for the organic materials or acidification for the carbonaceous materials) and its purification by other gases, potential poisons for the reduction step;

3. Reduction of $\mathrm{CO}_{2}$ to graphite.

Each step of this procedure, however, might introduce its own contaminations. Treatment procedures constitute, at present, the limiting factor for AMS analyses in terms of sample throughput, background contamination (bkg), and measurement reproducibility.

'Corresponding author. Email: fabio.marzaioli@unina2.it. 
The background for the entire procedure is checked and corrected by running the entire pretreatment procedure on several kinds of ${ }^{14} \mathrm{C}$ blanks (processed blanks). Improvements on the treatment phases, thus decreasing the background introduced by these procedures (Southon 2007), allow the measurement of samples with low ${ }^{14} \mathrm{C}$ values. High degrees of reproducibility for the graphite production ensure the feasibility of high-precision AMS $(\sigma=0.3 \%)$ (Steier et al. 2004) while stabilizing current yields and isotopic fractionation of the targets. A systematic study of contamination sources and isotopic fractionation phenomena and their relationships with the imposed treatment conditions can lead to an improvement of the AMS technique precision and sensitivity (Hua et al. 2001). Usually, most of the contamination during sample treatment is due to the $\mathrm{CO}_{2}$ gas production, handling (Step 2), and reduction (Step 3) (Aerts-Bijma et al. 1997). While combustion processes are well characterized in terms of controlling parameters (i.e. amounts of reagents, temperature, and reaction times), graphitization processes are less securely linked with reaction conditions because of their composite nature.

Graphitization is achievable via 2 kinds of reducers:

- Hydrogen $\left(\mathrm{H}_{2}\right)$ using $\mathrm{Fe}$ or $\mathrm{CO}$ as catalysts at $600-700^{\circ} \mathrm{C}$ with a cold finger for water trapping (Vogel et al. 1984);

- Zinc (Zn) using Fe or CO as catalysts (Jull et al. 1986; Slota et al. 1987) and $\mathrm{TiH}_{2}$ (Vogel 1992).

The Vogel (1992) sealed-tube zinc reaction uses molecular hydrogen for the $\mathrm{CO}_{2}$ reduction as well, but $\mathrm{H}_{2}$ is furnished in solid form $\left(\mathrm{TiH}_{2}\right.$ powder). Titanium hydrate (melting point $=440{ }^{\circ} \mathrm{C}$ ) melts at the reaction temperature $\left(500^{\circ} \mathrm{C}\right)$, releasing hydrogen and starting the sealed-tube zinc reduction of $\mathrm{CO}_{2}$, behaving in a similar way to the hydrogen used for the $\mathrm{H}_{2}$ reaction $\left(\mathrm{CO}_{2}+2 \mathrm{H}_{2} \rightarrow \mathrm{C}_{\text {graphite }}+\right.$ $2 \mathrm{H}_{2} \mathrm{O}$ ). Typically, the amounts of $\mathrm{TiH}_{2}$ used (5-10 mg to reduce $1 \mathrm{mg}$ of $\mathrm{C}$ ) are not sufficient to ensure total reduction of the whole $\mathrm{CO}_{2}$ to graphite. The zinc, reducing the $\mathrm{H}_{2} \mathrm{O}$ produced, recycles $\mathrm{H}_{2}$ from the water molecule $\left(\mathrm{H}_{2} \mathrm{O}+\mathrm{Zn} \rightarrow \mathrm{ZnO}+\mathrm{H}_{2}\right)$, allowing the $\mathrm{CO}_{2}$ reduction to be complete. Filamentous graphite is formed after about $8 \mathrm{hr}$ on the $\mathrm{Fe}(2-4 \mathrm{mg})$ or CO powder (Xu et al. 2007). For this reaction, the role of zinc is similar to the cold finger for the hydrogen reduction: it removes water from gaseous equilibrium and regenerates molecular hydrogen. Chain reactions ( $\mathrm{Xu}$ et al. 2007) take place around $500{ }^{\circ} \mathrm{C}$, and can be expressed as follows:

$$
\begin{gathered}
\mathrm{TiH}_{2} \rightarrow \mathrm{Ti}+\mathrm{H}_{2} \\
\mathrm{CO}_{2}+\mathrm{H}_{2} \rightarrow \mathrm{CO}+\mathrm{H}_{2} \mathrm{O} \\
\mathrm{CO}+\mathrm{H}_{2} \rightarrow \mathrm{C}_{\text {graphite }}+\mathrm{H}_{2} \mathrm{O} \\
\mathrm{Zn}+\mathrm{H}_{2} \mathrm{O} \rightarrow \mathrm{H}_{2}+\mathrm{ZnO}
\end{gathered}
$$

Other reduction reactions can take place (Jull et al. 1986; Slota et al. 1987):

$$
\begin{aligned}
& \mathrm{CO}_{2}+\mathrm{Zn} \rightarrow \mathrm{CO}+\mathrm{ZnO} \\
& 2 \mathrm{CO} \rightarrow \mathrm{C}_{\text {graphite }}+\mathrm{CO}_{2}
\end{aligned}
$$

Hydrogen reduction is most commonly used and ensures high, stable $\mathrm{C}$ current yields in the ion source, permitting high-precision measurements and low backgrounds (equivalent ages of $54 \mathrm{kyr}$; Santos et al. 2004), which makes it applicable for ${ }^{14} \mathrm{C}$ dating of all kinds of organic samples. The hydrogen reaction must, however, take place in a single reaction chamber thermoregulated by means 
of an oven and a cooling system, because of the coexistence of a hot spot $\left(700{ }^{\circ} \mathrm{C}\right.$ for the graphite deposition) and a cold finger (less than $-20^{\circ} \mathrm{C}$ for the water trapping).

Sealed-tube zinc reaction, on the contrary, because of the use of $\mathrm{Zn}$ powder, can take place in 1 reactor at a homogeneous temperature $\left(500^{\circ} \mathrm{C}\right)$, allowing simultaneous reductions in the muffle furnace, and thus an increase in the production rates of graphite. The zinc reaction background usually results in higher contaminations (equivalent age of $50 \mathrm{kyr}$ for $1 \mu \mathrm{g} \mathrm{C}$ ) and isotopic fractionation than the hydrogen (Xu et al. 2007). Hydrogen reaction is commonly accepted as the best tool for AMS ${ }^{14} \mathrm{C}$ target preparation, but sealed-tube zinc reaction is more productive and cost-efficient than the hydrogen graphitization method, resulting in a very effective practical method for graphitization of contemporary and/or relatively young samples. Zinc reaction, because of the use of solid reagents and the possibility of pretreatments on solid reagents, has the potential for further improvements in terms of background. Since January 2006, in order to increase CIRCE graphite production throughput to more than 1000 samples/yr (Passariello et al. 2006), we decided to test and apply the sealedtube zinc reduction method in our ${ }^{14} \mathrm{C}$ preparation laboratory.

In this paper, we present our experience with sealed-tube zinc reduction and present the results of tests carried out aiming to increase CIRCE sample throughput, decrease the background observed in the literature, and stabilize fractionation effects occurring during sample processing.

\section{MATERIALS AND METHODS}

\section{Sample Combustion}

Organic samples, chemically pretreated according to their type (see Introduction), are combusted in sealed quartz tubes with copper oxide via muffle furnace combustion. This procedure was implemented with the aim to minimize background contamination and isotopic fractionation observed using the old static-chamber combustion method (Lubritto et al. 2004). One-meter quartz tubes (6 $\mathrm{mm}$ OD $\times 4 \mathrm{~mm}$ ID) are flame-melted into 6 quartz combustion vessels (about $17 \mathrm{~cm}$ each). Before combustion, each vessel is filled at the bottom with copper (II) oxide (CuO rods $100 \mathrm{mg}$ ) reaction tubes. The amount of $\mathrm{CuO}$ used ensures stoichiometric oxygen sufficient to oxidize about $7 \mathrm{mg}$ of organic carbon. Reaction tubes undergo an entire cycle of combustion at $920^{\circ} \mathrm{C}$ for $6.5 \mathrm{hr}$ in open air. This procedure (Vandeputte et al. 1996) decreases the ${ }^{14} \mathrm{C}$ background, burning out a fraction of carbon potentially present on the quartz and copper oxide original materials (Hua et al. 2001). An amount of sample able to ensure about $2 \mathrm{mg}$ of carbon (depending on its $\mathrm{C}$ concentration) is weighed directly into the pretreated reaction tubes with clean iron spatulas. For organic samples rich in $\mathrm{S}$ impurities (which generate $\mathrm{SO}_{2}$, a poison for the graphitization reactions), the reactor is also filled with prebaked $\left(5 \mathrm{hr}\right.$ at $\left.800^{\circ} \mathrm{C}\right)$ silver wires. Reactors are marked and, finally, transferred to the zinc line (Figure 1) via 1/4-inch Swagelok ${ }^{\circledR}$ Ultra-Torr ${ }^{\circledR}$ high-vacuum fittings. Each reactor is evacuated using a membrane/turbo-pump system; after a few minutes, measured values reached $10^{-4}$ torr. Samples under dynamic vacuum conditions are sealed inside a $\sim 10 \mathrm{~mm}$ area of the reactor tube using a propane/oxygen torch $\left(1350^{\circ} \mathrm{C}\right)$. The presence of a vacuometer connected to the line before the pumping system allows monitoring any irregularity during the torch-sealing operations, to discard samples that have experienced air intrusion. Sealed samples are then transferred to a refractory brick with holes, which entirely insulate each sealed sample from the others, thus avoiding chain explosions during the combustion phase. Simultaneous combustions take place inside a muffle furnace for $6.5 \mathrm{hr}$ at $920^{\circ} \mathrm{C}$. The timer-controlled muffle furnace can hold 2 bricks of 32 samples, allowing the combustion of 64 samples a day. After combustion overnight and after the temperature of the samples decreases (about $4 \mathrm{hr}$ after the end of combustion; Hua et al. 2001), samples are identified via a grid engraved on the upper face of each brick. 
To the vacuum system

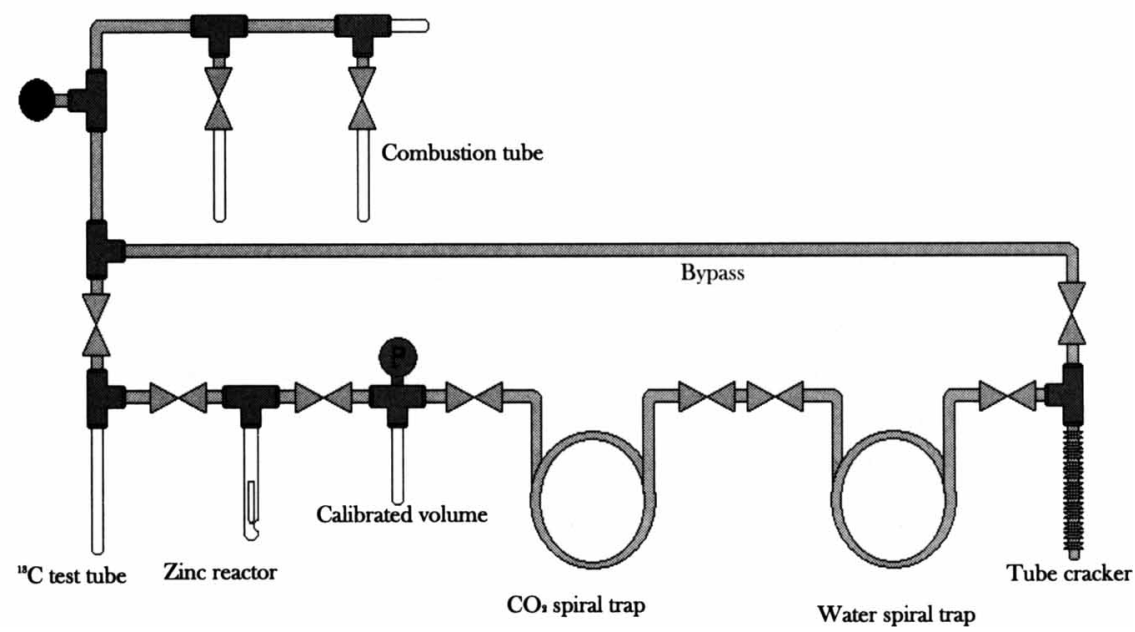

Figure 1 The CIRCE zinc preparation line. Spiral traps partially immersed in dry ice/ethanol and $\mathrm{LN}_{2}$ baths allow trapping yields near 100\%, avoiding the so-called snow effect (Bertolini et al. 2005) and reducing isotopic fractionation virtually to zero.

\section{$\mathrm{CO}_{2}$ Purification}

Combustion gases are mainly composed of $\mathrm{CO}_{2}$ and other highly oxidized gaseous molecules (i.e. $\mathrm{NO}_{\mathrm{x}}, \mathrm{SO}_{2}$ ) produced by the excess of oxygen released by copper oxide (see "Sample Combustion"). $\mathrm{CO}_{2}$ undergoes purification into a steel cryogenic line (Figure 1). Sealed quartz tubes holding gases produced by combustion are broken into a previously evacuated tube cracker. These gases are forced to pass through $\mathrm{H}_{2} \mathrm{O}$ and $\mathrm{CO}_{2}$ spiral traps (Bertolini et al. 2005) which, chilled using ethanol/dry ice and liquid nitrogen $\left(\mathrm{LN}_{2}\right)$ baths, respectively, cause $\mathrm{H}_{2} \mathrm{O}$ and $\mathrm{CO}_{2}$ condensation. Other gases, noncondensable in the traps, are discarded via the pumping system. The mass of purified $\mathrm{CO}_{2}$ is barometrically determined into a known volume, calibrated by means of certified and internal $\mathrm{C}$ standards (i.e. Thermo Finnigan cyclohexanon, SR2 [soil]), allowing yield calculations for the combustion process. If the $\mathrm{C}$ yield of combustion is close to $100 \%$, no isotopic fractionation happens between the carbon isotopic signal of the solid samples and the $\mathrm{CO}_{2}$ produced by combustion (Bottinga 1969). Purified $\mathrm{CO}_{2}$ is finally graphitized and an aliquot $(\sim 1 \mathrm{mg} \mathrm{C})$ is preserved into sealed Pyrex ${ }^{\circledR}$ test tubes for isotopic ratio mass spectrometry (IRMS) dual-inlet ${ }^{13} \mathrm{C}$ analysis.

\section{Sample Graphitization}

Purified $\mathrm{CO}_{2}$ can be switched to 2 different graphitization reaction lines. $\mathrm{CO}_{2}$ destined to produce hydrogen-reduced graphite is transferred using a Rotaflo ${ }^{\circledR}$ transfer vessel to the multisample (4 chambers represented in Figure 2a) hydrogen reaction line. $\mathrm{CO}_{2}$ destined for zinc reaction remains in the line and is cryogenically transferred to the pretreated (see "Zinc Reactor Pretreatment") zinc reactor (Figure $2 b$ ), where it is flame-sealed in after combustion yield determination. Sealed reactors containing purified $\mathrm{CO}_{2}$ are marked and transferred to a refractory brick, allowing the reduction to take place without any sample mix-up by means of an engraved identification grid. On average, 32 reactions take place simultaneously in a time-controlled muffle furnace set at $560{ }^{\circ} \mathrm{C}$ for $4 \mathrm{hr}$ and at $550^{\circ} \mathrm{C}$ for the following $4 \mathrm{hr}$. Produced graphite is preserved inside the reactors until its measurement, when it will be pounded into a 1-mm Al standard cathode (National Electrostatics Corp.). 
HYDROGEN REACTOR

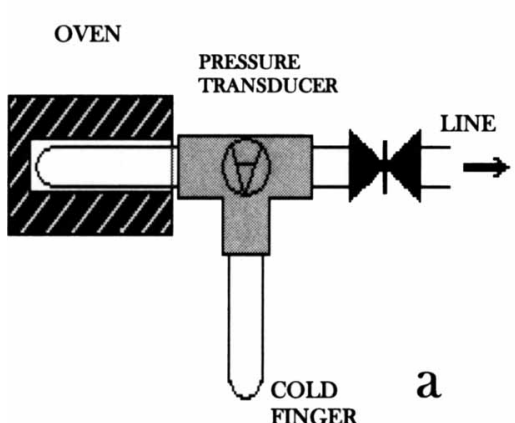

ZINC REACTOR

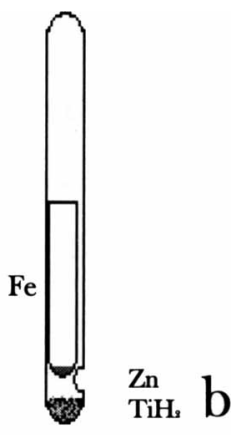

Figure 2 Scheme of the reaction chambers. $\mathrm{CO}_{2}$ is transferred into each reactor and reduced to graphite. a) For hydrogen reaction, pressure is continuously acquired, oven temperature is controlled with a LabView software interface, and a cold finger is cooled down via a dry ice/ethanol slush. b) Zinc reaction takes place in a clean Pyrex ${ }^{\circledR}$ reactor containing on its bottom Zn and $\mathrm{TiH}_{2}$ powders. Graphite develops in the internal 6-mm vessel above the Fe powder.

\section{Zinc Reactor Pretreatment}

Usually, 6 external Pyrex tubes are produced from 1-m tubing via torch melting. At about $1 \mathrm{~cm}$ from the tube bottom, a restriction is realized in order to avoid direct contact between the $\mathrm{Zn}-\mathrm{TiH}_{2}$ powder and the 6-mm test tube. Prepared 9-mm Pyrex tubes, and, separately, 6-mm bacteriological test tubes filled with about $2 \mathrm{mg}$ of $\mathrm{Fe}$ powder, undergo thermal treatment in a muffle furnace at $560^{\circ} \mathrm{C}$ for $5 \mathrm{hr}$.

Zinc and titanium hydrate powders used to fill reaction tubes are separately pretreated $(2 \mathrm{~g}$ for each reactive) into vacuum-sealed, clean Pyrex tubes $\left(9 \mathrm{~mm} \mathrm{OD} \times 12 \mathrm{~cm}\right.$ length) at $360^{\circ} \mathrm{C}$ for $3 \mathrm{hr}$. Each cleaned 9-mm external tube is filled with the correct amount of pretreated $\mathrm{Zn}$ and $\mathrm{TiH}_{2}$ powder and then cleaned 6-mm test tubes are gently laid down using tweezers. These reactors undergo the last muffle furnace pretreatment, just before their usage, at $300^{\circ} \mathrm{C}$ for $1 \mathrm{hr}$ in open air and are, after their cooling for $20 \mathrm{~min}$, attached to the zinc line ready to the hold purified $\mathrm{CO}_{2}$ sample.

The zinc reactors are composed of an external $(9 \mathrm{~mm} \mathrm{OD} \times 10 \mathrm{~cm}$ length) Pyrex tube holding at its bottom a mixture of $\mathrm{TiH}_{2}(7-10 \mathrm{mg})$ and $\mathrm{Zn}(35-40 \mathrm{mg})$ and a Pyrex bacteriological test tube $(6 \mathrm{~mm}$ OD $\times 4$-m length) filled with $2 \mathrm{mg}$ of Alfa Aesar ${ }^{\circledR} \mathrm{Fe}$ powder (Xu et al. 2007) (Figure 2b). For each scheduled ${ }^{14} \mathrm{C}$ beam time, a sufficient number of reactors (40) are prepared to host the previously combusted and purified $\mathrm{CO}_{2}$.

\section{Measuring ${ }^{14} \mathrm{C}$ with the CIRCE AMS System}

Usually, 1 standard wheel of 40 samples is composed of 4 untreated Alfa Aesar graphites, 4 processed Alfa Aesar blanks, 4 processed IAEA C3 standards (cellulose), 1 processed IAEA C5 (wood), 1 processed IAEA C6 (sucrose), 2 NIST OxII (oxalic acid), and 24 processed unknown samples, including replicate samples. All processed replicates result from different treatments. The untreated graphite is used to check the machine background, while processed blank samples are representative of preparation-induced background. After checking the absence of dependence of ${ }^{14} \mathrm{C}$ isotopic ratios from the cathode position, we use 1 of the $4 \mathrm{C} 3$ standard cathodes for normalization purposes and the other standards for quality control.

Measured values of processed blanks allowed us to quantify contamination and isotopic fractionation. Control standards, by means of comparison with their nominal isotopic pMC values (Rozan- 
ski et al. 1992), gave us the opportunity to quantify the accuracy and the precision of the lab procedures for combustion and graphitization. From January to September 2006, about 227 samples were graphitized using the zinc line and measured with our AMS system.

\section{RESULTS AND DISCUSSION}

\section{Zinc Line ${ }^{14} \mathrm{C}$ Background Characterization}

Assuming that any difference of the processed blank from zero is attributable to contamination of modern atmospheric $\mathrm{CO}_{2}$ during sample $\mathrm{CO}_{2}$ production, handling, and reduction, it is possible to express the processed blank measured ${ }^{14} \mathrm{C}$ signal ( $\mathrm{pMC}_{\text {meas }}$ ) as the contribution of 2 sources: the theoretical unprocessed blank $\left(\mathrm{pMC}_{\mathrm{blk}}=0\right)$ and the atmospheric contamination $\left(\mathrm{pMC}_{\mathrm{atm}}>0\right)$.

Performing an isotopic mass balance:

$$
\mathrm{pMC}_{\text {meas }} \mathrm{m}_{\text {meas }}=\mathrm{pMC}_{\mathrm{atm}} \mathrm{m}_{\mathrm{atm}}+\mathrm{pMC}_{\mathrm{blk}} \mathrm{m}_{\mathrm{blk}}=\mathrm{pMC}_{\mathrm{atm}} \mathrm{m}_{\mathrm{atm}}
$$

where the subscript meas refers to the values of $\mathrm{C}$ mass $\left(\mathrm{C}_{\text {meas }}=\mathrm{C}_{\mathrm{atm}}+\mathrm{C}_{\mathrm{blk}}\right)$ and the measured pMC of the processed blank and atm and blk are the $\mathrm{C}$ mass and pMC of the atmospheric $\mathrm{C}\left(\mathrm{CO}_{2}\right)$ contamination and the untreated blank $\left(\mathrm{pMC}_{\mathrm{blk}}=0\right)$, respectively.

The equation below allows the expression of the mass of atmospheric $\mathrm{C}$ contamination of each blank:

$$
\mathrm{m}_{\mathrm{atm}}=\frac{\mathrm{pMC}_{\text {meas }} \mathrm{m}_{\mathrm{blk}}}{\mathrm{pMC}_{\mathrm{atm}}-\mathrm{pMC} \mathrm{C}_{\text {meas }}}
$$

By measuring the ${ }^{14} \mathrm{C}$ signature and the initial mass of carbon of the processed blank and hypothesizing the value of atmospheric contamination, this value quantifies the quality of procedural blanks, allowing comparison among different procedures.

Some $30 \%$ of the measured samples were procedural blanks of Alfa Aesar graphite, processed with our laboratory protocol (combustion + graphitization), with masses of carbon graphitized $\left(\mathrm{C}_{\mathrm{blk}}\right)$ ranging from 0.155 to $5.61 \mathrm{mg}$. Blank ${ }^{14} \mathrm{C}$ apparent ages are measured using processed blank pMC values normalized to the normalization standard (see "Measuring ${ }^{14} \mathrm{C}$ with the CIRCE AMS System"), corrected for actual fractionation, and no machine background subtracted. Machine background during zinc wheel measurements on unprocessed Alfa Aesar graphite led to a mean pMC value of $0.017 \pm 0.003$ (mean \pm standard error, $n=24$ ), or $69.8 \pm 1.1 \mathrm{kyr}$.

The zinc line blank curve (as apparent age vs. mass of carbon graphitized mass) is represented in Figure 3. Values obtained from different kinds of pretreatments, performed to test and optimize our starting reaction conditions, are plotted. In particular, procedure A (described in "Zinc Reactor Pretreatment") was first applied without any glass thermal cleaning nor any reagent purification, at a reduction temperature of $530-550^{\circ} \mathrm{C}$. Procedure $\mathrm{B}$ includes glass thermal cleaning, while procedure $\mathrm{C}$ indicates also reagent purification. In the case of procedure $\mathrm{D}$, reduction temperatures were increased to $550-560{ }^{\circ} \mathrm{C}$ to reduce process-induced isotopic fractionation (see "Zinc Line Isotopic Fractionation Characterization"). The mean values and standard deviations of atmospheric contaminations for each graphitization procedure are reported in Table 1. For each measured procedural blank ( $\mathrm{pMC}_{\text {meas }}$ ), according to Equation 1, atmospheric contamination value $\left(\mathrm{C}_{\mathrm{atm}}\right)$ was calculated,

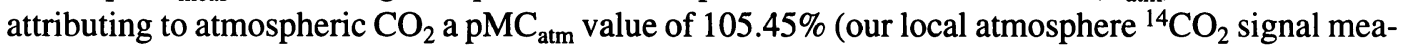
sured in open air in 2006). 


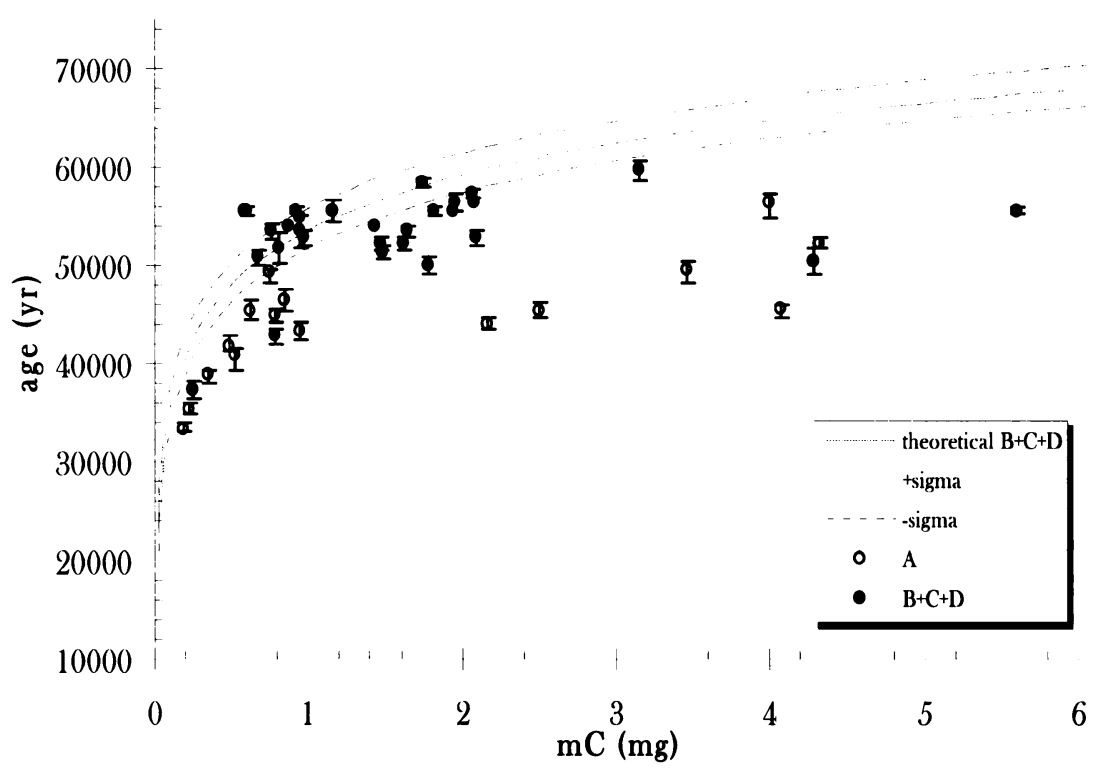

Figure 3 Zinc line blank curve (apparent age of the blank vs. $\mathrm{mg} \mathrm{C}$ graphitized). The apparent age of the blank is measured on the fractionation-corrected pMC. The mass of $\mathrm{C}$ graphitized refers to the equivalent mass of $\mathrm{C}$ introduced into the zinc reactor. The solid and dashed lines represent the theoretical behavior corresponding to the atmospheric contamination best fitting our operating conditions ( $1.2 \pm 0.3 \mathrm{mg}$; see text for details).

Table 1 Comparison of the atmospheric contamination of Alfa Aesar graphite samples processed by applying 4 different procedures of sealed-tube zinc graphitization at the CIRCE lab.

\begin{tabular}{lllll}
\hline Procedure & $\begin{array}{l}\text { Nr of } \\
\text { replicates }\end{array}$ & $\begin{array}{l}\text { Mean value of atmospheric } \\
\text { contamination }(\mu \mathrm{g} \mathrm{C})\end{array}$ & $\begin{array}{l}\text { Standard } \\
\text { deviation }\end{array}$ & $\begin{array}{l}\text { Standard } \\
\text { error }\end{array}$ \\
\hline A & 16 & 4.7 & 3.3 & 0.82 \\
B & 6 & 2.7 & 2.5 & 1.0 \\
C & 10 & 1.8 & 1.5 & 0.5 \\
D & 13 & 1.8 & 0.8 & 0.2 \\
\hline
\end{tabular}

A reduction of atmospheric contamination can be observed between the graphite produced using treated (procedure B) versus untreated (procedure A) glass reactors, their difference being about 1.5 times the propagated standard error, but the relative scatter is larger for procedure B. Pretreatment of reagents (procedure $C$ ) seems to decrease the scatter of measurements around their mean values, standardizing the initial conditions of the material used for different reactions, but does not influence the mean level of atmospheric contamination. An increase of reduction temperature to $550-560^{\circ} \mathrm{C}$ again does not show any significant influence on the atmospheric contamination, but did decrease the scatter of blanks around their mean value. Because there is no significant background improvement, procedures B, C, and D are grouped together, leading to an error-weighted mean atmospheric contamination of $1.2 \pm 0.3 \mathrm{mg}$ (weighted mean \pm standard error of the mean) of modern carbon as representative of the atmospheric contamination of our actual (combustion + graphitization + measurement) zinc process. For procedures $\mathrm{B}+\mathrm{C}+\mathrm{D}$, a flat behavior in the apparent age is observed for masses $>0.5 \mathrm{mg}$ in the apparent age curve (Figure 3 ). This apparent age, measured from the mean pMC of the blanks $(0.13 \pm 0.08$ mean value \pm standard deviation $)$, is $53.0 \pm 4.6$ $\mathrm{kyr}$, and is chosen as representative of the zinc process background. It is used to correct the measure- 
ments of unknown samples of $\mathrm{C}$ mass higher than $0.5 \mathrm{mg}$. The mean apparent age of the zinc process is comparable to the apparent age $(53.3 \pm 2.5 \mathrm{kyr}$, Passariello et al. 2006) obtained in our lab for the $\mathrm{H}_{2} / \mathrm{CO}_{2}$ process (sealed-tube combustion + hydrogen reduction), but it showed a greater variability in the ${ }^{14} \mathrm{C}$ content of the blanks. On the other hand, the result turns out to be significantly better than expected: measured modern $\mathrm{CO}_{2}$ contamination introduced during zinc line sample processing is comparable to mean atmospheric contamination introduced by hydrogen using the same combustion procedures (Tuniz et al. 1998; Hua et al. 2001).

\section{Zinc Line Isotopic Fractionation Characterization}

In order to characterize isotopic fractionations occurring during sample processing, a series of IRMS measurements were conducted at different steps of the Alfa Aesar graphite processing (combustion, graphitization, and AMS measurement).

We measured 3 independently weighed, unprocessed Alfa Aesar graphite samples via an elemental analyzer (1112 Thermo Finnigan), Conflo II (Thermo Finnigan), and Delta ${ }^{\text {plus }}$ isotopic ratio mass spectrometer (typical precision $0.2 \% \circ$ on $\delta^{13} \mathrm{C}$ values). The measured and calibrated EA/IRMS $\delta^{13} \mathrm{C}$ value of the untreated graphite was $-20.7 \pm 0.2 \%$ (mean value \pm standard deviation, $n=3$ ). We refer to this value as the reference $\delta^{13} \mathrm{C}$ for the Alfa Aesar graphite.

IRMS $\delta^{13} \mathrm{C}$ measured values of sealed-tube combusted $\mathrm{CO}_{2}$, not calibrated against any sealed-tube sample, from Alfa Aesar graphite samples was $-21.15 \pm 0.01 \%$ (mean value \pm standard deviation, $n=45$ ). Calibration of this value with respect to sealed-tube combusted solid samples (IAEA C series) resulted in $-20.55 \pm 0.05 \%$ o. Thus, the combusted Alfa Aesar graphite $\delta^{13} \mathrm{C}$ uncalibrated value is consistent with the EA/IRMS measurements only at level of $2.25 \sigma$, indicating a small $(-0.4 \pm$ $0.2 \%$ ) and reproducible isotopic fractionation during vacuum-sealed combustion. This phenomenon is probably due to the solid samples' structure, which induces inertia in its vacuum combustion (see "Sample Combustion"). However, calibration of the results cancels out this ${ }^{13} \mathrm{C}$ discrimination induced by the combustion procedure, indicating a fractionation not specific to sample type.

EA/IRMS measurements of 26 residues of processed Alfa Aesar graphite samples (procedure A + $\mathrm{B}+\mathrm{C} ; 530-550^{\circ} \mathrm{C}$ ), normalized using IRMS solid standards, led to a value of $-26.4 \pm 4.3 \%$ (mean value \pm standard deviation). This indicates an average process-induced (combustion + graphitization) fractionation of $5.3 \%$ with a large scatter (4.3\%o). Following Botinga (1969), we tried to decrease fractionation processes occurring during graphitization by increasing the graphitization temperature to $550-560^{\circ} \mathrm{C}$ and processed 13 more Alfa Aesar graphites. The resulting calibrated EA-IRMS value is $-25.5 \pm 3.4 \%$ o. The increased temperature slightly reduced both the absolute value and the dispersion of the negative discrimination on the heavier stable isotopes of carbon, but did not cancel the isotopic fractionation. The current fractionation of the zinc process (procedure $\mathrm{D}$ ) results in $-4.4 \pm 3.4$ delta points, higher than that given in $\mathrm{Xu}$ et al. (2007). The vacuum-combustion-induced fractionation $(-0.4 \pm 0.2)$ is negligible (about $10 \%$ ) with respect to the ${ }^{13} \mathrm{C}$ fractionation induced by the zinc reduction process, underlying the latter as the keyhole process to be considered for reducing ${ }^{13} \mathrm{C}$ process discrimination.

The $\delta^{13} \mathrm{C}$ of zinc blank samples graphitized both at $530-550$ and $550-560{ }^{\circ} \mathrm{C}$ was also measured online by AMS with respect to the $\mathrm{C} 3$ normalization standard. The average values were $-20.4 \pm 7.6 \%$ o and $-23.9 \pm 6.2 \%$ (mean \pm standard deviation), respectively. Their agreement with the EA-IRMS values of unprocessed graphite show that, again, on average, the normalization with graphitized standards cancels out the fractionation (both due to preparation and to the machine), resulting in high accuracy for the system. Individual values show a dispersion higher than the EA/IRMS observed dispersion, reflecting the high variability of fractionation. 
Additional experimental work will be performed with the aim to reduce the variability of zincprocess-induced fractionation. It is worth noting that ${ }^{14} \mathrm{C}$ isotopic ratios are not affected by such variability, as fractionation corrections are applied individually on the basis of the on-line $\delta^{13} \mathrm{C}$ measurements.

\section{Zinc Line Accuracy Characterization}

Accuracy of the system can be quantified by comparing measured standards with their consensus values. A $z$ score variable can be defined as the difference of each measured standard $\mathrm{pMC}_{\mathrm{i}}\left(\sigma_{\mathrm{i}}=\right.$ uncertainty affecting its measurement) from its consensus value ( $\mathrm{pMC}_{\text {consensus }} \pm \sigma_{\text {consensus }}$ ), divided by the error affecting this difference. This variable is expected to be distributed around a mean value $\left(\mu_{\mathrm{z}}\right)$ of zero in absence of systematic errors with a standard deviation $\left(\sigma_{\mathrm{z}}\right)$ of 1 for good estimations of each standard measuring uncertainty $\left(\sigma_{\mathfrak{i}}\right)$.

About $15 \%$ of the samples processed using the zinc line were quality-check standards. Available standards data (34 measurements including discarded and lost standards) can be used to study accuracy and reproducibility of the zinc procedure. As mentioned, most of the control standards were IAEA C series. Measured values are isotopic fractionation-corrected, with the blank subtracted for the mean value of the procedural blank (see "Zinc Line ${ }^{14} \mathrm{C}$ Background Characterization") and normalized to the C3 standard (see "Measuring ${ }^{14} \mathrm{C}$ with the CIRCE AMS System"). Results of measured pMC are reported in Table 2. Our reproducibility-excluding IAEA C4, which was measured only twice and has a very low ${ }^{14} \mathrm{C}$ content-varies comparably to the observed machine reproducibility (i.e. the dispersion of pMC values measured with cathodes from the same treatment, $\sim 0.3 \%$ ) (Terrasi et al. 2007) for modern samples to a few percent for depleted standards (Table 2). The measured reproducibility is comparable to published values for both the hydrogen (Santos et al. 2004) and zinc methods (Xu et al. 2007).

Table 2 Measured ${ }^{14} \mathrm{C}$ abundance of procedural standards expressed as pMC affected by fractionation correction, blank subtraction, and normalized with respect to IAEA C3 and their consensus value (errors in parentheses) (Rozanski et al. 1992; NBS SRM 4990C certificate).

\begin{tabular}{llllcr}
\hline $\begin{array}{l}\text { Sample } \\
\text { name }\end{array}$ & $\begin{array}{l}\text { Nr of } \\
\text { replicates }\end{array}$ & $\begin{array}{l}\text { Mean } \\
\text { pMC }\end{array}$ & $\begin{array}{l}\text { Standard } \\
\text { deviation }\end{array}$ & $\begin{array}{l}\text { Relative } \\
\text { error }(\%)\end{array}$ & $\begin{array}{l}\text { Consensus } \\
\text { value }\end{array}$ \\
\hline IAEA C3 & 7 & 129.25 & 0.26 & 0.21 & $129.41(0.06)$ \\
IAEA C4 & 2 & 0.23 & 0.12 & 52 & $0.32(0.12)$ \\
IAEA C5 & 9 & 23.13 & 0.49 & 2.1 & $23.05(0.02)$ \\
IAEA C6 & 7 & 150.53 & 0.79 & 0.53 & $150.61(0.11)$ \\
NIST OxII & 8 & 134.49 & 0.37 & 0.27 & $134.07(0.04)$ \\
\hline
\end{tabular}

The measured $z$ variable is distributed around a mean value of -0.01 , with a standard deviation of 1.21 (observed standard error on $n=33$ samples was 0.21 ) (Figure 4). The mean $z$ value indicates a good accuracy for pretreated standards and a good error estimate for the measured ${ }^{14} \mathrm{C}$ values.

\section{CONCLUSIONS}

The treatment phase of samples for $\mathrm{AMS}{ }^{14} \mathrm{C}$ ratio determination represents the main drawback to the entire system procedure. Combustion and $\mathrm{CO}_{2}$ reduction subphases cover most of the variability observed during an AMS measurement. Correct characterization of the preparation phase in terms of introduced background, accuracy, and precision is necessary for a correct measurement of ${ }^{14} \mathrm{C}$ values. Systematic studies on combustion and graphitization phases can lead to an understanding of 


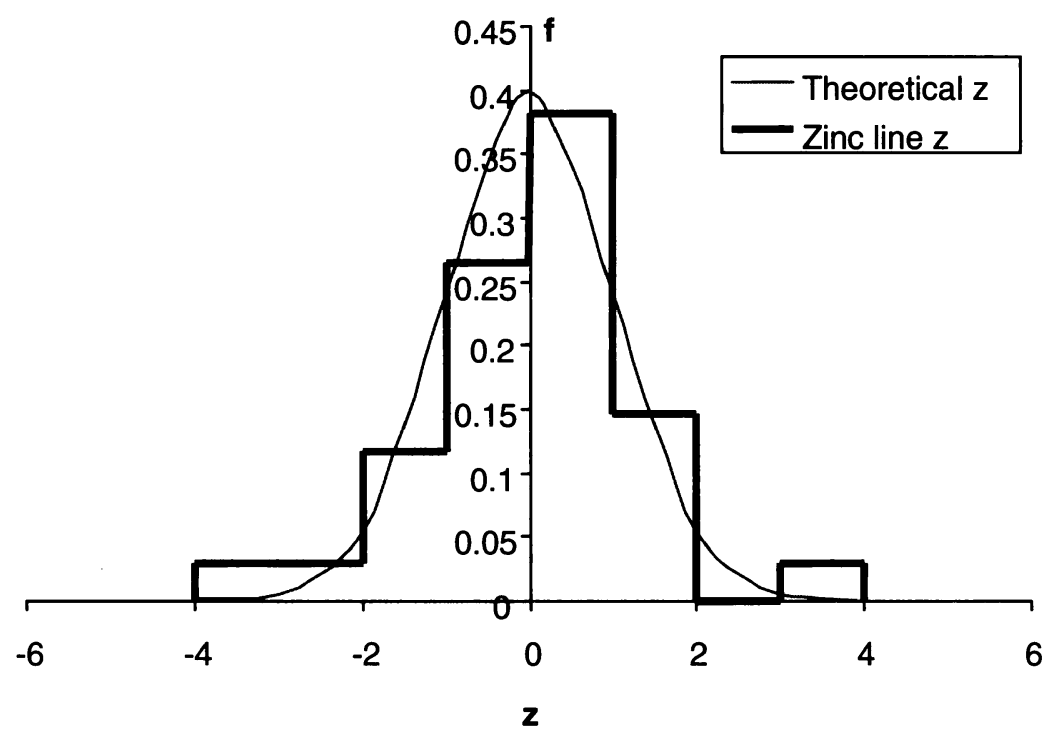

Figure 4 Histogram of the observed $z$ scores for the measured ${ }^{14} \mathrm{C}$ values of control standards (frequency density) compared to the theoretical $z$ distribution.

the biases induced by sample preparation, and to their reduction. Improvements of the CIRCE AMS laboratory zinc line led to background levels comparable to published hydrogen values and to a good reproducibility and accuracy of graphitized samples in terms of ${ }^{14} \mathrm{C}$ measurements.

Measured isotopic fractionation effects, induced during graphite production by zinc reaction, constitute the negative heavy isotope discrimination driving process. Adjustment of the reduction temperature with respect to literature values (i.e. increased temperature range) allowed us to slightly reduce, both in absolute value and dispersion, the ${ }^{13} \mathrm{C}$ fractionation; however, the values still remain higher than published hydrogen reaction and zinc values. The status of our zinc line makes it a feasible alternative for pretreating samples of ages $<40 \mathrm{kyr}$, with a potential productivity rate of 40 samples per day per analyst.

\section{ACKNOWLEDGMENTS}

We are grateful to the Trumbore-Xu laboratory (ESS at the University of California, Irvine), especially to Xiaomei Xu for her help with basic knowledge about sealed-tube zinc reaction, and to Alessandro Zagaria for help with the preparation of samples.

\section{REFERENCES}

Aerts-Bijma AT, Meijer HAJ, van der Plicht J. 1997. AMS sample handling in Groningen. Nuclear Instruments and Methods in Physics Research B 123(1-4): 221-5.

Andersen HH, Demortier G. 2004. Editorial. Nuclear Instruments and Methods in Physics Research B 226(12):1-2.

Bertolini T, Rubino M, Lubritto C, D'Onofrio A, Marzaioli F, Passariello I, Terrasi F. 2005. Optimized sample preparation for isotopic analyses of $\mathrm{CO}_{2}$ in air: systematic study of precision and accuracy dependence on driving variables during $\mathrm{CO}_{2}$ purification process. Journal of Mass Spectrometry 40(8):1104-8.

Bottinga Y. 1969. Calculated fractionation factors for carbon and hydrogen isotope exchange in the system calcite-carbon dioxide-graphite-methane-hydrogenwater vapor. Geochimica et Cosmochimica Acta 33(1):49-64.

Calzolai G, Chiari M, García Orellana I, Lucarelli F, Migliori A, Nava S, Taccetti F. 2006. The new external beam facility for environmental studies at the Tandetron accelerator of LABEC. Nuclear Instruments and 
Methods in Physics Research B 249(1-2):928-31.

Druffel ERM, Griffin S, Hwang J, Komada T, Beaupre SR, Druffel-Rodriguez KC, Santos GM, Southon J. 2004. Variability of monthly radiocarbon during the 1760 s in corals from the Galapagos Islands. Radiocarbon 46(2):627-31.

Fowler AJ, Gillespie R, Hedges REM. 1986. Radiocarbon dating of sediments. Radiocarbon 28(2A):44150.

Green JW. 1963. Wood cellulose. In: Whistler RL, editor. Methods in Carbohydrate Chemistry. New York: Academic Press. p 9-21.

Hoefs J. 1987. Stable Isotope Geochemistry. 3rd edition. Berlin: Springer-Verlag. 241 p.

Hua Q, Jacobsen GE, Zoppi U, Lawson EM, Williams AA, Smith AM, McGann MJ. 2001. Progress in radiocarbon target preparation at the ANTARES AMS Centre. Radiocarbon 43(2A):275-82.

Hughen KA, Overpeck JT, Lehman SJ, Kashgarian M, Southon J, Peterson LC, Alley R, Sigman DM. 1998. Deglacial changes in ocean circulation from an extended radiocarbon calibration. Nature 391(6662):658.

Jull AJT, Donahue DJ, Hatheway AL, Linick TW, Toolin LJ. 1986. Production of graphite targets by deposition from $\mathrm{CO} / \mathrm{H}_{2}$ for precision accelerator ${ }^{14} \mathrm{C}$ measurements. Radiocarbon 28(2A): 191-7.

Longin R. 1971. New method of collagen extraction for radiocarbon dating. Nature 230(5291):241-2.

Lubritto C, Rogalla D, Rubino M, Marzaioli F, Passariello I, Romano M, Spadaccini G, Casa G, Di Leva A, De Cesare N, D'Onofrio A, Gialanella L, Imbriani G, Palmieri A, Roca V, Rolfs C, Sabbarese C, Strieder F, Schuermann D, Terrasi F. 2004. Accelerator mass spectrometry at the 4MV Dynamitron Tandem in Bochum. Nuclear Instruments and Methods in Physics Research B 222(1-2):255-60.

Marzaioli F, Lubritto C, Battipaglia G, Passariello I, Rubino M, Detlef R, Strumia S, Miglietta F, D'Onofrio A, Cotrufo MF, Terrasi F. 2005. Reconstruction of past $\mathrm{CO}_{2}$ concentration at a natural $\mathrm{CO}_{2}$ vent site using radiocarbon dating of tree rings. Radiocarbon 47(2): 257-63.

Mook WG, Streurman HJ. 1983. Physical and chemical aspects of radiocarbon dating. In: Mook WG, Waterbolk HAT, editors. Proceedings of the First International Symposium " ${ }^{14} \mathrm{C}$ and Archaeology." Groningen 1981. PACT 8:31-55.

Passariello I, Marzaioli F, Lubritto C, Rubino M, D'Onofrio A, De Cesare N, Borriello G, Casa G, Palmieri A, Rogalla D, Sabbarese C, Terrasi F. 2006. Radiocarbon sample preparation at the CIRCE AMS laboratory in Caserta, Italy. Radiocarbon 49(2):225-32.

Randerson JT, Enting IG, Schuur EAG, Caldeira K, Fung IY. 2002. Seasonal and latitudinal variability of troposphere $\Delta^{14} \mathrm{CO}_{2}$ : post bomb contributions from fossil fuels, oceans, the stratosphere, and the terrestrial bio- sphere. Global Biogeochemical Cycles 16(4):1112, doi: 10.1029/2002GB001876.

Rozanski K, Stichler W, Gonfiantini R, Scott EM, Beukens RP, Kromer B, van der Plicht J. 1992. The IAEA ${ }^{14} \mathrm{C}$ Intercomparison Exercise 1990. Radiocarbon 34(3):506-19.

Santos GM, Southon JR, Druffel-Rodriguez KC, Griffin S, Mazon M. 2004. Magnesium perchlorate as an alternative water trap in AMS graphite sample preparation: a report of sample preparation at KCCAMS at the University of California, Irvine. Radiocarbon 46(1): 165-73.

Six J, Callewaert P, Lenders S, De Gryze S, Morris SJ, Gregorich EG, Paul EA, Paustian K. 2002. Measuring and understanding carbon storage in afforested soils by physical fractionation. Soil Science Society of America Journal 66(6): 1981-7.

Slota Jr PJ, Jull AJT, Linick TW, Toolin LJ. 1987. Preparation of small samples for ${ }^{14} \mathrm{C}$ accelerator targets by catalytic reduction of CO. Radiocarbon 29(2):303-6.

Southon J. 2007. Graphite reactor memory - Where is it from and how to minimize it? Nuclear Instruments and Methods in Physics Research B 259(1):288-92.

Steier P, Dellinger F, Kutschera W, Priller A, Rom W, Wild EM. 2004. Pushing the precision limit of ${ }^{14} \mathrm{C}$ AMS. Radiocarbon 46(1):5-16.

Terrasi F, Rogalla D, De Cesare N, D'Onofrio A, Lubritto C, Marzaioli F, Passariello I, Rubino M, Sabbarese C, Casa G, Palmieri A, Gialanella L, Imbriani G, Roca V, Romano M, Sundquist M, Loger R. 2007. A new AMS facility in Caserta/Italy. Nuclear Instruments and Methods in Physics Research B 259(1):14-7.

Trumbore S. 2000. Age of soil organic matter and soil respiration: radiocarbon constraints on belowground C dynamics. Ecological Applications 10(2):399-411.

Tuniz C, Bird JR, Fink D, Herzog GF. 1998. Accelerator Mass Spectrometry: Ultrasensitive Analysis for Global Science. Boca Raton: CRC Press. 408 p.

Vandeputte K, Moens L, Dams R. 1996. Improved sealed-tube combustion of organic samples to $\mathrm{CO}_{2}$ for stable isotope analysis, radiocarbon dating and percent carbon determinations. Analytical Letters 29(15): 2761-73.

Vogel JS. 1992. Rapid production of graphite without contamination for biomedical AMS. Radiocarbon 34(3):344-50.

Vogel JS, Southon JR, Nelson DE, Brown TA. 1984. Performance of catalytically condensed carbon for use in accelerator mass spectrometry. Nuclear Instruments and Methods in Physics Research B 5(2):289-93.

Xu X, Trumbore SE, Zheng S, Southon JR, McDuffee KE, Luttgen M, Liu JC. 2007. Modifying a sealed tube zinc reduction method for preparation of AMS graphite targets: reducing background and attaining high precision. Nuclear Instruments and Methods in Physics Research B 259(1):320-9. 